\title{
High-dose chemotherapy with autologous peripheral blood stem cell transplantation for choriocarcinoma: A case report and literature review
}

\author{
EIKO YAMAMOTO $^{1,2}$, KAORU NIIMI $^{1}$, KAYO FUJIKAKE $^{1}$, TETSUYA NISHIDA $^{3}$, \\ MAKOTO MURATA ${ }^{3}$, AYAKO MITSUMA ${ }^{4}$, YUICHI ANDO ${ }^{4}$ and FUMITAKA KIKKAWA ${ }^{1}$ \\ Departments of ${ }^{1}$ Obstetrics and Gynecology, ${ }^{2}$ Healthcare Administration and ${ }^{3}$ Hematology and \\ Oncology, Nagoya University Graduate School of Medicine; ${ }^{4}$ Department of Clinical Oncology \\ and Chemotherapy, Nagoya University Hospital, Nagoya, Aichi 466-8550, Japan
}

Received April 6, 2016; Accepted May 30, 2016

DOI: $10.3892 / \mathrm{mco} .2016 .1011$

\begin{abstract}
Choriocarcinoma is a malignant gestational trophoblastic neoplasia (GTN) and one of the curable types of gynecological cancer. However, $10 \%$ of choriocarcinoma patients have a poor prognosis, particularly when they have metastasis, apart from pulmonary metastasis, or do not go into remission by the second chemotherapeutic regimen. We herein present the case of a 36-year-old patient who had choriocarcinoma with metastases to the lungs, liver and kidneys. The 5th and 6th regimens with cisplatin for choriocarcinoma failed and the patient developed brain metastases. She was then treated with four cycles of high-dose ifosfamide, carboplatin and etoposide (ICE) with blood progenitor cell support after confirming the effectiveness of ICE at normal doses. The serum human chorionic gonadotropin (hCG) level was $140,009 \mathrm{mIU} / \mathrm{ml}$ at the start of high-dose ICE and the patient tolerated this regimen well. However, the beneficial effect was decreasing with each successive course of treatment, with the lowest level of hCG at $103 \mathrm{mIU} / \mathrm{ml}$ after the fourth course. The patient did not achieve complete remission and succumbed to the disease 4 months after the last chemotherapy. The findings of the present case and a review of the related literature suggest that high-dose ICE with stem cell rescue may be considered as a viable treatment option for a multi-drug resistant choriocarcinoma or GTN.
\end{abstract}

Correspondence to: Dr Eiko Yamamoto, Department of Healthcare Administration, Nagoya University Graduate School of Medicine, 65 Tsurumai-cho, Showa-ku, Nagoya, Aichi 466-8550, Japan E-mail: yamaeiko@med.nagoya-u.ac.jp

Key words: choriocarcinoma, gestational trophoblastic neoplasia, high-dose chemotherapy, ifosfamide, multi-drug resistance, peripheral blood stem cell transplantation

\section{Introduction}

Gestational trophoblastic neoplasia (GTN) describes a spectrum of tumors that arise from placental trophoblasts, including invasive mole, choriocarcinoma, placental site trophoblastic tumor (PSTT) and epithelial trophoblastic tumor (ETT). Choriocarcinoma is very responsive to chemotherapy and the survival rate has increased to $\leq 90 \%$. However, it is difficult to achieve complete remission (CR) in patients with multiple metastases or metastasis to organs other than the lungs. Multi-drug chemotherapy should be the first-line regimen for high-risk GTNs, including choriocarcinoma $(1,2)$. Etoposide, methotrexate, actinomycin D, cyclophosphamide and vincristine (EMA/CO) (3) and methotrexate, etoposide and actinomycin D (MEA) (2) are used as first-line regimens, with an effectiveness rate of $\sim 80 \%$. Etoposide, cisplatin, methotrexate and actinomycin D (EP/EMA) (4), fluorouracil and actinomycin D (FA) (5) and paclitaxel, cisplatin and etoposide (TP/TE) (6) have been reported as second- or third-line regimens.

High-dose chemotherapy (HDC) with autologous peripheral blood stem cell transfusion is widely used for hematological malignancies, such as lymphoma and myeloma. In the present case, this treatment was used for an intractable choriocarcinoma after seven other regimens failed to achieve CR.

\section{Case report}

The patient was a 36-year-old Japanese woman, gravida 2, para 2, who visited a local hospital as she thought she had become pregnant. However, the pregnancy was proven to be a complete hydatidiform mole and the patient underwent a hysterectomy. She was diagnosed with low-risk GTN after 3 months (WHO stage: score, I:0) (1) and received three courses of chemotherapy with methotrexate $\left(20 \mathrm{mg} / \mathrm{m}^{2}\right.$ body surface, days 1-5). The level of human chorionic gonadotropin (hCG) increased 2 years after remission of low-risk GTN and examination of a bronchoscopic biopsy of the lung pathologically confirmed choriocarcinoma. Whereas computed 
tomography (CT) and magnetic resonance imaging (MRI) revealed the presence of metastases in both lungs, the liver and both kidneys (WHO stage:score IV:17). The patient received six courses of EP, as her doctor considered this regimen to be effective against germ cell tumors. Partial pneumonectomy of the right lung was also performed, as the hCG level started to increase after the fifth course of treatment (Fig. 1). The metastases in the kidneys grew rapidly after the operation, and the patient received five courses of EMA/CO, which proved to be ineffective. The patient was then referred to our institute (Nagoya University Hospital, Nagoya, Japan) and received two courses of MEA, one course of FA, one course of TP/TE and three courses of biweekly paclitaxel and cisplatin (TP). These chemotherapies were partially effective, although the hCG level was gradually increasing and MRI detected two metastases (4 and $9 \mathrm{~mm}$ ) in the brain after the second course of biweekly TP. The patient underwent CyberKnife radiosurgery with 20 Gy to each brain lesion, and the brain metastases disappeared.

Administration of high-dose ifosfamide, carboplatin and etoposide (ICE) was then decided, since none of the normal-dose regimens achieved a remission, whereas there was a case report of a patient with choriocarcinoma who achieved a CR after four courses of high-dose ICE (7). Informed consent was obtained from the patient and her husband following approval by the Ethics committee of the Nagoya University Graduate School of Medicine. The effectiveness of ICE at normal doses was confirmed (mini ICE, Table I). After 3 weeks, high-dose cyclophosphamide (CPA; $2 \mathrm{~g} / \mathrm{m}^{2}$, days 1-2) was administered, followed by granulocyte colony-stimulating factor (G-CSF; $10 \mathrm{mg} / \mathrm{m}^{2} /$ day subcutaneously) and $470 \times 10^{6}$ peripheral blood stem cells $\left(8.1 \times 10^{6} / \mathrm{kg}\right)$ were collected on the 15 th day of high-dose CPA. The cells were divided into four packs and frozen. The hCG level was 140,009 $\mathrm{mIU} / \mathrm{ml}$. High-dose ICE (Table I) was administered after the second course of mini ICE, and $2.0 \times 10^{6} / \mathrm{kg}$ stem cells were transfused on the 7th day of high-dose ICE. Prophylactic administration of acyclovir 1,000 mg/day, fluconazole $400 \mathrm{mg} / \mathrm{day}$, trimethoprim-sulfamethoxazole combination $1 \mathrm{~g} / \mathrm{day}$ and levofloxacin $500 \mathrm{mg} /$ day were initiated on the day prior to high-dose ICE. The adverse events were grade 4 neutropenia, anemia and thrombopenia, grade 3 febrile neutropenia and hepatic dysfunction, grade 2 creatinine elevation, oral ulcers, anorexia, fatigue, sensory neuropathy and grade 1 desquamation (Common Terminology Criteria for Adverse Events, version 4.0). G-CSF $5 \mathrm{~g} / \mathrm{kg} /$ day was administered starting on the next day after the stem cell transfusion until the neutrophil count had recovered to $0.5 \times 10^{9}$ cells $/ 1$. The patient required red blood cell and platelet transfusions to maintain a red blood cell count of $\geq 8.0 \mathrm{~g} / \mathrm{dl}$ and a platelet cell count of $\geq 20 \times 10^{9} / 1$. No bacteria were detected in the culture of arterial and venous blood whenever the patient had a fever $\geq 38.5^{\circ} \mathrm{C}$. The patient developed dyspnea and hypoxemia, which were caused by pneumonia and carcinomatous lymphangiosis due to the neutropenia and multiple lung metastases, and required oxygenation from the 3 rd to the 12 th day of each course of high-dose ICE.

The level of hCG decreased to $1,989 \mathrm{mIU} / \mathrm{ml}$ after the first course of high-dose ICE. However, the effect of the treatment
Table I. Mini and high-dose ifosfamide, carboplatin and etoposide (ICE) regimens.

\begin{tabular}{lcrr}
\hline Agents & Dose & Hours & Days \\
\hline Mini ICE & & & \\
$\quad$ Ifosfamide & $2,000 \mathrm{mg} / \mathrm{m}^{2}$ d.i.v. & 1 & $1-2$ \\
Etoposide & $150 \mathrm{mg} / \mathrm{m}^{2}$ d.i.v. & 11 & $1-2$ \\
Carboplatin & $200 \mathrm{mg} / \mathrm{m}^{2}$ d.i.v. & 1 & $1-2$ \\
Etoposide & $150 \mathrm{mg} / \mathrm{m}^{2}$ d.i.v. & 11 & $1-2$ \\
High-dose ICE & & & \\
Ifosfamide & $3,000 \mathrm{mg} / \mathrm{m}^{2}$ d.i.v. & 1 & $1-4$ \\
Etoposide & $200 \mathrm{mg} / \mathrm{m}^{2}$ d.i.v. & 11 & $1-3$ \\
Carboplatin & $300 \mathrm{mg} / \mathrm{m}^{2}$ d.i.v. & 1 & $1-4$ \\
Etoposide & $200 \mathrm{mg} / \mathrm{m}^{2}$ d.i.v. & 11 & $1-3$ \\
\hline
\end{tabular}

d.i.v., drip intravenous infusion.

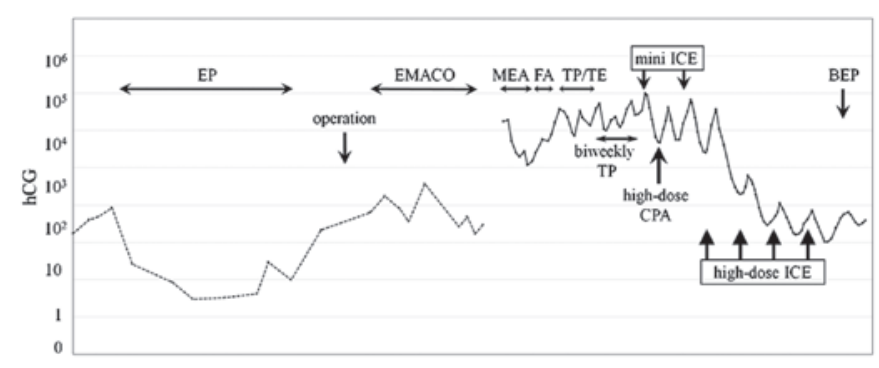

Figure 1. Changes in the serum level of human chorionic gonadotropin (hCG) and the treatment progress of choriocarcinoma. The broken line indicates the hCG $\beta$-subunit (ng/ml) measured at the first hospital and the solid line indicates the intact $\mathrm{hCG}(\mathrm{mIU} / \mathrm{ml})$ measured at our institute. EP, etoposide and cisplatin; EMA/CO, etoposide, methotrexate, actinomycin D, cyclophosphamide and vincristine; MEA, methotrexate, etoposide and actinomycin D; FA, fluorouracil and actinomycin D; TP/TE, paclitaxel, cisplatin and etoposide; CPA, cyclophosphamide; BEP, bleomycin, etoposide and cisplatin; ICE, ifosfamide, carboplatin and etoposide.

was gradually decreasing with each successive course of treatment, and the level of hCG had not reached the cut-off level $(0.5 \mathrm{mIU} / \mathrm{ml})$ after four courses. The lowest level was $103 \mathrm{mIU} / \mathrm{ml}$. Positron emission tomography-CT revealed multiple metastases, although each lesion decreased in size after high-dose ICE. It was difficult to continue this regimen, as there was no report of $>$ four courses of high-dose ICE being effective and safe for GTN, and it was unclear how many courses would be required to achieve remission ( $\mathrm{hCG} \leq 0.5 \mathrm{mIU} / \mathrm{ml}$ ). The patient wished to continue with chemotherapy and underwent one course of bleomycin, etoposide and cisplatin (BEP); however, the level of hCG increased and she succumbed to the disease 4 months later. The patient had undergone treatment for 26 months without achieving remission.

\section{Discussion}

We demonstrated the effectiveness and tolerability of high-dose ICE with peripheral blood stem cell rescue for choriocarcinoma. Our patient developed chemoresistance 


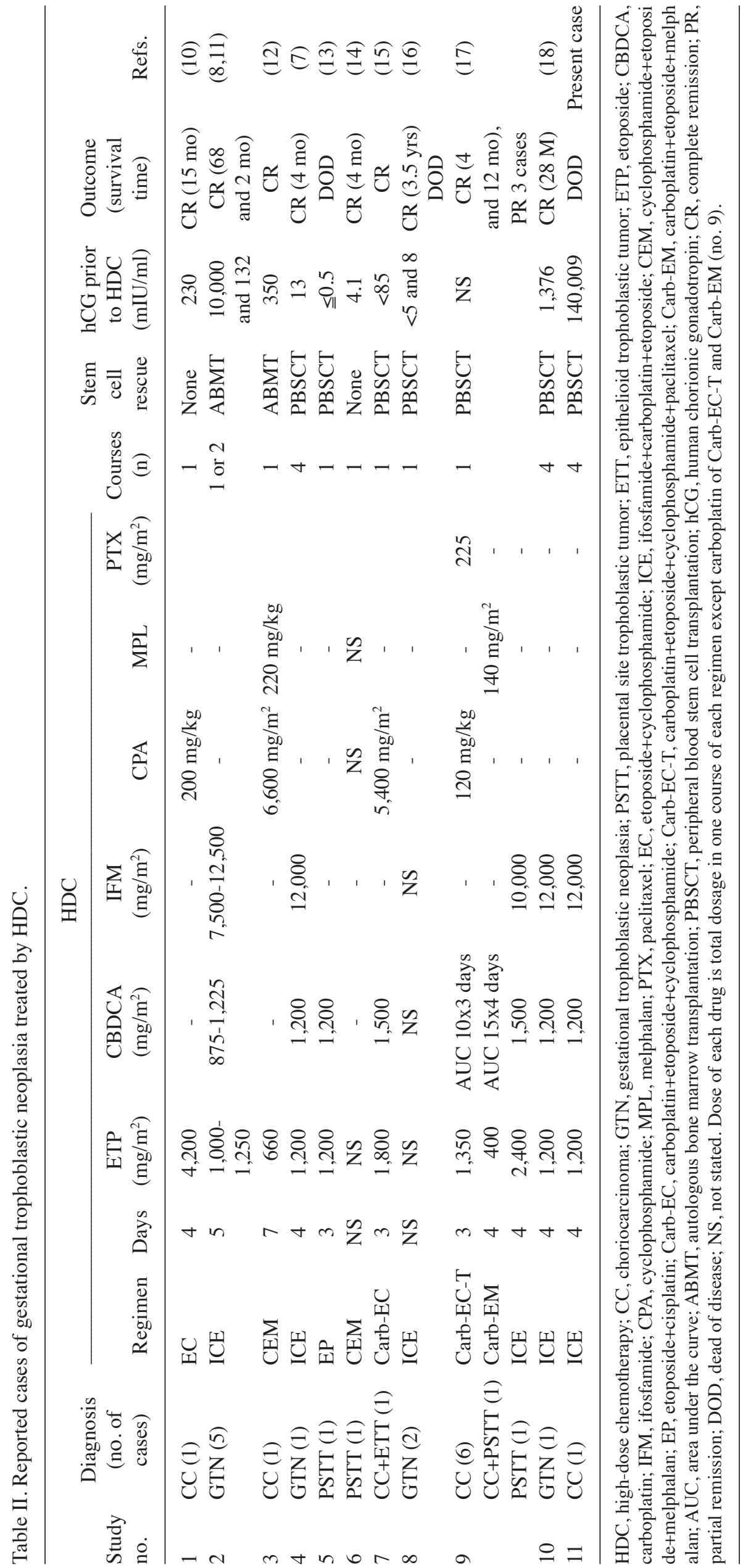


from the 5th course of EP onwards, with decreasing effectiveness of each successive regimen. However, high-dose ICE exhibited the highest effectiveness among all the regimens the patient had received. Previous reports of high-dose ICE for intractable malignancies reported side effects, such as oral ulcers, esophagitis, nausea and diarrhea, in $\sim 100 \%$ of the cases, and liver dysfunction and neurological disorders in $\sim 30 \%$ of the cases (8). In terms of myelosuppression, $36 \%$ of the patients had infection or sepsis, and $18 \%$ succumbed due to severe side effects. It should be noted that even mini ICE is a regimen associated with a high risk of severe side effects (9). We successfully collaborated with hematologists, nurses and pharmacologists who specialize in HDC and stem cell transfusion.

To evaluate HDC for GTN, we performed an extensive literature search through MEDLINE using the terms 'high-dose chemotherapy' and 'gestational trophoblastic neoplasia' and/or 'choriocarcinoma.' After excluding male cases or non-gestational choriocarcinoma, our search yielded 21 cases in 11 articles between 1991 and 2013 (Table II) (7,8,10-18). Two cases reported by Jean-Pierre Lotz in 1991 (11) were included in the 5 cases reported in 1995 by the same author (8). Of the 22 cases, including our patient, 14 patients were pathologically diagnosed as choriocarcinoma, PSTT and ETT, and the remaining 8 patients were clinically diagnosed as GTN. Although seven regimens were used with different doses for the 22 cases, the majority of the regimens included etoposide, carboplatin and ifosfamide, and the major regimen was ICE. Only 3 cases received four courses of HDC, as the latest 2 cases followed the treatment of the first case, who was successfully treated and overcame multi-drug resistance with brain metastasis. CR was achieved in 11 of the 22 patients (50\%) and this CR rate appears to be very promising for intractable malignancies, although the survival time after CR in 4 cases was <4 months (cases no. 2, 4, 6 and 9). However, cases with favorable results were reported more frequently than unsuccessful cases, and the CR rate of report no. 9 was $25 \%$ ( 2 of 8 cases). The study by Lotz et al reported on 69 cycles of high-dose ICE for 39 patients with several types of malignancies and suggested that germ cell tumors and GTNs are the only tumors that may be considered for HDC in cases with highly refractory disease (8). It is difficult to reach any firm conclusion regarding the efficacy of HDC for GTN with only a limited number of reports. However, these results suggest that HDC may be included in a series of treatments that may prove to be curative in multi-drug resistant GTN.

Our case did not achieve remission with high-dose ICE, as the effectiveness of the treatment gradually diminished (Fig. 1). The hCG level was $140,009 \mathrm{mIU} / \mathrm{ml}$ prior to the first course of high-dose ICE. However, the hCG levels in the 11 cases who were cured were $<10,000 \mathrm{mIU} / \mathrm{ml}$ prior to HDC (Table II). The two successful cases (nos. 4 and 10), who were treated with the same high-dose ICE regimen as the present case, exhibited hCG levels of 13 and 1,376 mIU/ml prior to treatment $(7,18)$. Case no. 4 had multiple metastases, including to the brain, and both cases were resistant to multiple regimens. Although the hCG level in our case was significantly higher compared with that in cases 4 and 10 , it decreased to 1/1,400 after four courses of high-dose ICE. These results suggest that multi-drug resistant GTN and choriocarcinoma with hCG levels $<1,000 \mathrm{mIU} / \mathrm{ml}$ may be curable by HDC.

\section{Acknowledgements}

We would like to thank Professor Tony Cripps (Nanzan University, Nagoya, Japan) for proofreading the English manuscript.

\section{References}

1. Ngan HY, Bender H, Benedet JL, Jones H, Montruccoli GC and Pecorelli S; FIGO Committee on Gynecologic Oncology: Gestational trophoblastic neoplasia, FIGO 2000 staging and classification. Int J Gynaecol Obstet 83 (Suppl 1): S175-S177, 2003.

2. Matsui H, Suzuka K, Iitsuka Y, Seki K and Sekiya S: Combination chemotherapy with methotrexate, etoposide, and actinomycin D for high-risk gestational trophoblastic tumors. Gynecol Oncol 78: 28-31, 2000.

3. Bower M, Newlands ES, Holden L, Short D, Brock C, Rustin GJ, Begent RH and Bagshawe KD: EMA/CO for high-risk gestational trophoblastic tumors: Results from a cohort of 272 patients. J Clin Oncol 15: 2636-2643, 1997.

4. Newlands ES, Mulholland PJ, Holden L, Seckl MJ and Rustin GJ: Etoposide and cisplatin/etoposide, methotrexate, and actinomycin D (EMA) chemotherapy for patients with high-risk gestational trophoblastic tumors refractory to EMA/cyclophosphamide and vincristine chemotherapy and patients presenting with metastatic placental site trophoblastic tumors. J Clin Oncol 18: 854-859, 2000.

5. Matsui H, Suzuka K, Iitsuka Y, Yamazawa K, Tanaka N, Mitsuhashi A, Seki K and Sekiya S: Salvage combination chemotherapy with 5-fluorouracil and actinomycin D for patients with refractory, high-risk gestational trophoblastic tumors. Cancer 95: 1051-1054, 2002.

6. Wang J, Short D, Sebire NJ, Lindsay I, Newlands ES, Schmid P, Savage PM and Seckl MJ: Salvage chemotherapy of relapsed or high-risk gestational trophoblastic neoplasia (GTN) with paclitaxel/cisplatin alternating with paclitaxel/etoposide (TP/TE). Ann Oncol 19: 1578-1583, 2008.

7. van Besien K, Verschraegen C, Mehra R, Giralt S, Kudelka AP, Edwards CL, Piamsonboom S, Termrungruanglert W, Champlin R and Kavanagh JJ: Complete remission of refractory gestational trophoblastic disease with brain metastases treated with multicycle ifosfamide, carboplatin, and etoposide (ICE) and stem cell rescue. Gynecol Oncol 65: 366-369, 1997.

8. Lotz JP, André T, Donsimoni R, Firmin C, Bouleuc C, Bonnak H, Merad Z, Esteso A, Gerota J and Izrael V: High dose chemotherapy with ifosfamide, carboplatin, and etoposide combined with autologous bone marrow transplantation for the treatment of poor-prognosis germ cell tumors and metastatic trophoblastic disease in adults. Cancer 75: 874-885, 1995.

9. Fields KK, Zorsky PE, Hiemenz JW, Kronish LE and Elfenbein GJ: Ifosfamide, carboplatin, and etoposide: A new regimen with a broad spectrum of activity. J Clin Oncol 12: 544-552, 1994.

10. Collins RH Jr, White CS, Stringer CA and Fay JW: Successful treatment of refractory gestational trophoblastic neoplasm with high-dose etoposide and cyclophosphamide. Gynecol Oncol 43: 317-319, 1991.

11. Lotz JP, Machover D, Malassagne B, Hingh B, Donsimoni R, Gumus Y, Gerota J, Lam Y, Tulliez M, Marsiglia H, et al: Phase I-II study of two consecutive courses of high-dose epipodophyllotoxin, ifosfamide, and carboplatin with autologous bone marrow transplantation for treatment of adult patients with solid tumors. J Clin Oncol 9: 1860-1870, 1991.

12. Giacalone PL, Benos P, Donnadio D and Laffargue F: High-dose chemotherapy with autologous bone marrow transplantation for refractory metastatic gestational trophoblastic disease. Gynecol Oncol 58: 383-385, 1995.

13. Aoki Y, Kodama S, Kurata H, Kase H and Tanaka K: Failure of high-dose chemotherapy with peripheral blood stem cell support for refractory placental site trophoblastic tumor. Gynecol Obstet Invest 47: 214-216, 1999.

14. Rinne K, Shahabi S and Cole L: Following metastatic placental site trophoblastic tumor with urine beta-core fragment. Gynecol Oncol 74: 302-303, 1999. 
15. Knox S, Brooks SE, Wong-You-Cheong J, Ioffe O, Meisenberg B and Goldstein DP: Choriocarcinoma and epithelial trophoblastic tumor: Successful treatment of relapse with hysterectomy and high-dose chemotherapy with peripheral stem cell support: A case report. Gynecol Oncol 85: 204-208, 2002.

16. Markman M: Experience with platinum-based and high-dose chemotherapy in patients with gestational trophoblastic disease: Possible implications for future management. J Cancer Res Clin Oncol 130: 383-387, 2004.
17. El-Helw LM, Seckl MJ, Haynes R, Evans LS, Lorigan PC, Long J, Kanfer EJ, Newlands ES and Hancock BW: High-dose chemotherapy and peripheral blood stem cell support in refractory gestational trophoblastic neoplasia. Br J Cancer 93: 620-621, 2005 .

18. Benigno BB: High-dose chemotherapy with autologous stem cell support as salvage therapy in recurrent gestational trophoblastic disease. Int J Gynecol Cancer 23: 1331-1333, 2013. 